\title{
An Alternative Approach to Assessing Volume-of-Interest Accuracy Using CBCT and ImageJ Software: In Vitro Study
}

\author{
Ahmed Fadili, Naeda Alehyane, Abdelali Halimi, and Fatima Zaoui \\ Faculty of Dental Medicine, Mohammed V University, 10000 Rabat, Morocco \\ Correspondence should be addressed to Ahmed Fadili; fadiliahmedd@gmail.com
}

Received 28 June 2015; Revised 9 October 2015; Accepted 4 November 2015

Academic Editor: Kivanç Kamburoğlu

Copyright ( 2015 Ahmed Fadili et al. This is an open access article distributed under the Creative Commons Attribution License, which permits unrestricted use, distribution, and reproduction in any medium, provided the original work is properly cited.

\begin{abstract}
Aim. This study was performed to evaluate the accuracy and reliability of ImageJ software that we utilized to quantify the volume-ofinterest of buccal bone, in vitro study made with the dry skull of a sheep, and the comparison was applied with a reference method. Materials and Methods. A portion of the alveolar bone has been cut, then we built an acrylic model similar to this portion that we shut off, the model was inserted in the place of the piece that we cut, and we have scanned the skull afterwards. Four measurements were made by two examiners using the manual method and ImageJ software whereby DICOM images were extracted from CBCT. The accuracy and reliability were assessed using Student's test and ICC, when $P \leq 0.05$, the statistics are considered significant, and comparison is made employing SPSS and Excel. Results. The repeated measures of volume-of-interest using the manual method and the software method revealed no significant difference. Conclusion. As there is no statistical difference of volume measurements using manual method and ImageJ software, we concluded that the volume measurements with ImageJ software are reliable and accurate.
\end{abstract}

\section{Introduction}

Volume measurement is an important tool in many medical applications, such as evaluation of periodontal status and bone loss in Chinese with hemodialysis patients [1]. This tool is also important to demonstrate the association between periodontal bone loss and mucosal thickening of the maxillary sinus [2] and detect periodontal bone loss using CBCT and intraoral radiography [3]. Assessment of the correctness of the bone condition is essential for the diagnosis, treatment planning, and prognosis of periodontal disease [4], and information derived from probing the gingival tissues in association with diagnostic imaging provides guidelines for assessing the alveolar bone height and checking for the presence of vertical bone defects $[5,6]$. However, these methods do not reveal the real volume with cubic millimeter as a unit of measure; in their studies they use the height, depth, and width or linear measurement [1-8].

Nevertheless, despite the accuracy of linear measurement when we use two-dimensional (2D) images, some limitations occur, such as the superimposition and lacking in definition of important anatomical structures [6]. The advent of new generation cone-beam computed tomography (CBCT) has made it possible to overcome these limitations qualitatively and quantitatively evaluating the height and thickness of the alveolar bone and the length and thickness [9-11]. Moreover, this simple method of CBCT is not invasive, for its low cost, easy accessibility, and secure radiation compared with multislice computerized tomography. CBCT technology is developing rapidly either at the hardware or at software that would lead to a significant evolution of 3D imaging and many advances are on the horizon and also the volumetric measurement will be more accurate, reliable, and an imminent method for use. CBCT is a technique of obtaining the medical image using a beam of $\mathrm{X}$ rays in the form of a cone positioned in the middle of 2D detector; the detector circulates around the object to produce 2D image series that we can reconstruct into three-dimensional images deploying a modification of the original cone-beam algorithm developed by Feldkamp et al. [12].

This system is extensively used in various industrial and biomedical applications such as the micro-CT. Among the first clinical applications, where single photon emission tomography, angiography, and image guided radiotherapy are 

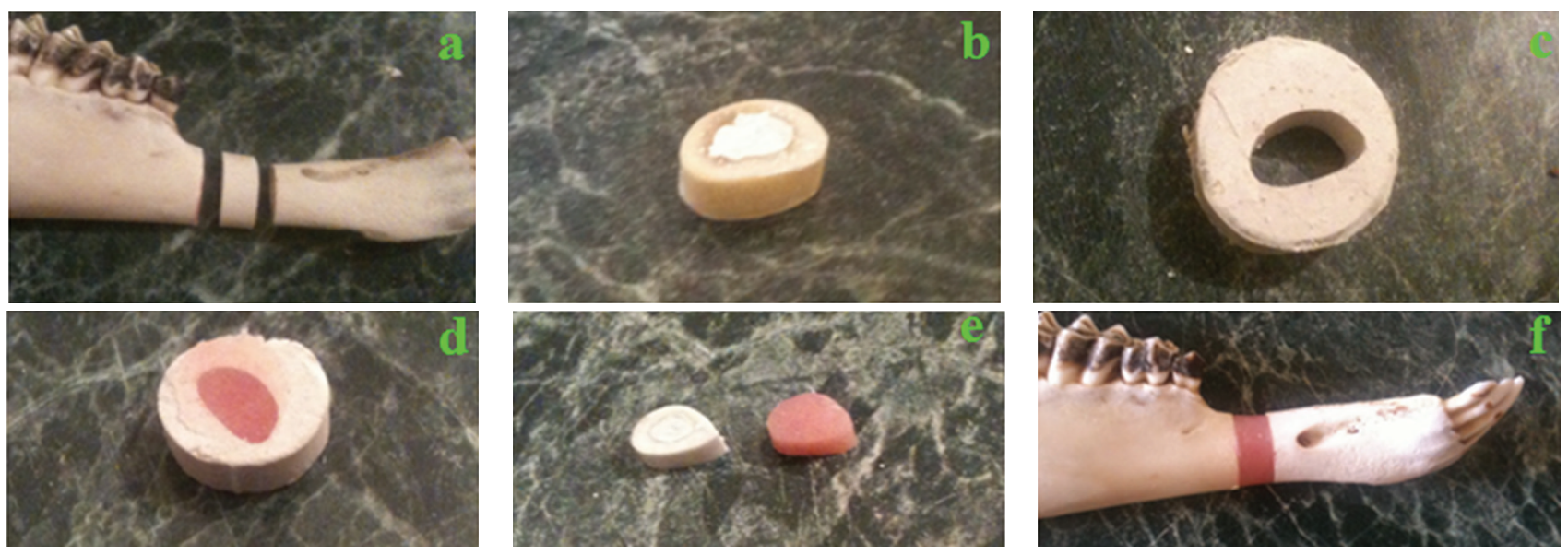

FIGURE 1: The steps followed to create the bone model.

used, CBCT scanners dedicated to the oral and maxillofacial region were the pioneers in the 1990s independently by Arai et al. [13] in Japan and Mozzo et al. in Italy [14]. CBCT has become more and more utilized for orthodontic diagnosis, treatment planning, and research. The use of CBCT for these purposes has been facilitated by the relative advantages of three-dimensional (3D) over $2 \mathrm{D}$ radiography and there has been a large expansion of interest in this new imaging technique.

There are many dental radiation dosimetry studies in the literature comparing traditional two-dimensional (2D) dental radiographs and CBCT [15]. Reported effective dose of a $2 \mathrm{D}$ panoramic radiograph ranges from 0.004 to $0.030 \mathrm{mSv}$ (4.0 to $30 \mathrm{uSv}$ ); a full mouth radiographic series utilizing $\mathrm{D}$ speed film and round collimation produces an effective dose level between 0.0349 and $0.388 \mathrm{mSv}$ (34.9 to $388 \mathrm{uSv}$ ). Standardized diagnostic reference levels for CBCT scanners are not yet available, and as a result, effective dose variations between the different $\mathrm{CBCT}$ units range from 0.027 to $1.073 \mathrm{mSv}$ (27 to $1073 \mathrm{uSv}$ ) [15]. Even if the CBCT is not used routinely in periodontal defect, CBCT tend to become the diagnostic standard, allowing visualization that simply could not be imagined just a few years ago and doses approximating that of conventional 2D radiology. However, in our study, we present an approach to quantifying volume measurement, using CBCT images for having an accurate bone evaluation; we need to measure real volume with cubic millimeter as a unit of assessment, for an eventual oral study requiring evaluation of the change of osseous volume before and after treatment or planning program.

\section{Materials and Methods}

2.1. Preparation of Samples. In vitro study was conducted using young dry skull of a sheep. The study protocol was approved by the local ethics committee and was conducted in accordance with the relevant laws for animal protection.

A portion of the mandible was cut (Figure 1(a)); a lack inside the portion is filled with dental impression plaster (Figure 1(b)) to facilitate the silicone impression and volume measurements; then dental impression plaster is applied to create a mold of the portion bone cut (Figure 1(c)); then the mold filled with acrylic (Figure $1(\mathrm{~d})$ ) by this manner we obtained the acrylic bone model (Figure 1(e)) which allows us to make another mold with silicone impression material; this silicone mold serves to fill it with distilled water. The model bone is inserted in the mandible in order to be scanned with CBCT (Figure 1(f)).

2.2. Testing the Visibility of the Acrylic Bone Model. As acrylic is not radiopaque, we have 3 times dipped it into a contrast product (Ultravist $300 \mathrm{mg}$ iodine/mL ink), $15 \mathrm{~min}$ between each immersion; bone model is inserted in the mandible; the mandible was then scanned with Sirona, SIDEXIS study, resolution: 6,250 pixels per $\mathrm{mm}$, at $85 \mathrm{kV}, 5 \mathrm{~mA}$, voxel size: $0.16 \times$ $0.16 \times 0.16 \mathrm{~mm}^{3}$, and slice thickness: $0.16 \mathrm{~mm}$ (Figure 2); the images were generated in the digital imaging and communications in medicine (DICOM) [16] which we extracted with ImageJ software. ImageJ (v 1.48 Java 1.6.0_20 64 bits) is a multiplatform software and open source, image processing, and analysis developed by the National Institutes of Health [17]. It is written in Java language and allows the addition of new functionality via plugins and macros. A clear visibility of volume-of-interest limits is shown (Figures 2 and 3).

2.3. Volume Measurement. In the first volume, a thin plastic is glued on the print of model (print built with silicone impression material), this plastic served as a cover to fill the cavity with distilled water, the filling is made with micropipette $(1 \mu \mathrm{L}-50 \mu \mathrm{L})$, and we continue to fill until eliminating the last air bubble. In the second volume, the scan data (DICOM images) were imported into ImageJ software, volume calculation made with Measure Stack, an algorithm developed by B. Dougherty [18].

2.4. Statistics. The measurements were recorded 17 times over 17 days (once per day) by two examiners; for each method we have the first and second measures; we use the interclass correlation coefficient (ICC) for assessing the intraexaminer reliability. The measurements were normally 


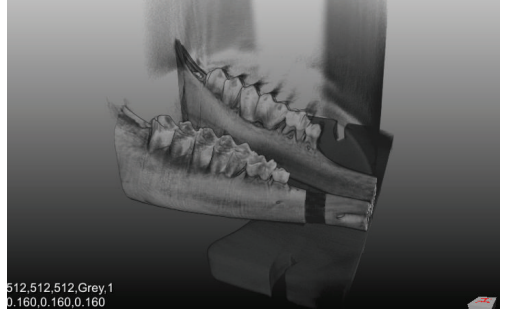

FIgURE 2: 3D visualization.

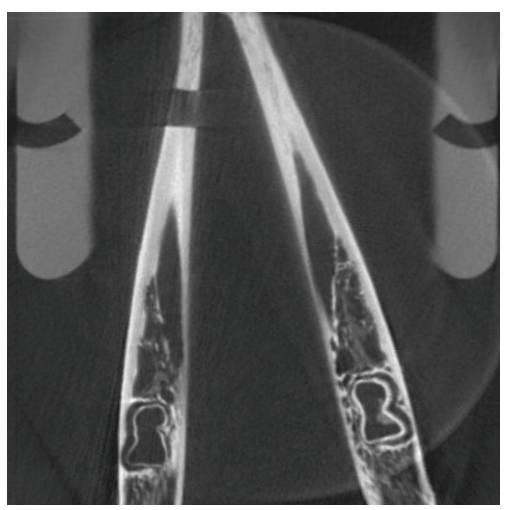

FIGURE 3: 2D visualization (one slice of DICOM image).

distributed; the mean and standard deviation were calculated and compared using Student's $t$-test.

All statistical calculations were done using the computer programs Microsoft Excel 2013 (Microsoft Corporation, New York, New York, USA) and Statistical Package for the Social Sciences software (version 21; SPSS, Chicago, Illinois, USA). Reliability and accuracy were assessed using Student's test and ICC.

\section{Results}

Using $t$-test, no significant differences were shown between the repeated VOI measurements (Table 1): between first software and second software VOI measurement (Table 2), between first manual and second manual VOI measurement (Table 3), and between first software and first manual VOI measurement (Table 4). Intraexaminer reliability of both the manual and the software method (using DICOM images of $\mathrm{CBCT}$ ) was high for all measurements, as indicated by ICC $(\geq 0.90)$; these results suggest that the methods are not examiner-dependent. Intraexaminers reliability is presented as ICC for the manual and software measurements.

\section{Discussions}

The purpose of this study was to verify whether the quantification of volume-of-interest buccal bone using DICOM images of CBCT with ImageJ software is accurate and reliable, compared with the manual method which is considered as
TABLE 1: The volume-of-interest measurements assessed with manual method and ImageJ software.

\begin{tabular}{|c|c|c|c|}
\hline \multicolumn{2}{|c|}{ Software measurements } & \multicolumn{2}{|c|}{ Manual measurements } \\
\hline $\begin{array}{l}\text { First } \\
\text { software }\left(\mathrm{mm}^{3}\right)\end{array}$ & $\begin{array}{c}\text { Second } \\
\text { software }\left(\mathrm{mm}^{3}\right)\end{array}$ & $\begin{array}{c}\text { First } \\
\text { manual }\left(\mathrm{mm}^{3}\right)\end{array}$ & $\begin{array}{c}\text { Second } \\
\text { manual }\left(\mathrm{mm}^{3}\right)\end{array}$ \\
\hline 385,45 & 387,54 & 381 & 384 \\
\hline 390,58 & 388,48 & 387 & 385 \\
\hline 380,3 & 389,27 & 374 & 387 \\
\hline 400,01 & 407,58 & 395 & 405 \\
\hline 383,45 & 381,25 & 378 & 379 \\
\hline 386,42 & 387,08 & 381 & 384 \\
\hline 364,9 & 360,37 & 357 & 356 \\
\hline 400,2 & 396,34 & 395 & 393 \\
\hline 376,89 & 380,81 & 373 & 378 \\
\hline 397,25 & 400,02 & 392 & 396 \\
\hline 392,36 & 402,06 & 385 & 398 \\
\hline 405,1 & 396,78 & 397 & 394 \\
\hline 389,99 & 388,57 & 385 & 383 \\
\hline 402 & 403,54 & 394 & 399 \\
\hline 359,25 & 362,91 & 353 & 357 \\
\hline 384,81 & 387,25 & 379 & 384 \\
\hline 392,12 & 395,5 & 375 & 390 \\
\hline
\end{tabular}

a reference method; the simulated bone is made with an acrylic material. We have been using repeated measurements of the same model and comparing the means to eliminate the high means variability of a specific measurement with different models and eliminate the height means variability of measurement occurring when the position of the skull deviates from ideal [19]. Therefore, we eliminate the effects of artifacts induced by discrepancies between the mathematical modeling and the actual physical imaging process [20]. We opted for the use of the acrylic model because it is bending resistance, simple to manipulate, soft, and resilient, and it is easy to distinguish it from the bone on the CBCT image due to its property of high transparency, in such manner that leads to an accurate segmentation (for accurate VOI determining). Moreover, its shape is still unchangeable during manipulation, which allows us to keep the volume constant. Height reliability and accuracy of VOI measurement are obtained, despite the fact that the examiners had no previous training of segmentation and analysis of CBCT image; we remedied this problem by calibrating the examiners. Evaluating the accuracy for measuring the buccal bone around dental implants, in their study, the buccal bone volume measurement was taken at two points: the most apical point possible and measurement away from the apical measurement in the direction toward the implant platform; the measurement was made using an optical microscope (Toolmakers Mitutoyos, Suzano, SP, Brazil) [21]. Many studies made to determine the volume graft in case of alveolar cleft defects, for example, study by Quereshy et al., 2012, use anatomic landmarks; three measurements were collected from CBCT images for each patient: facial width, facial height, and facial-palatal length. These values were used to calculate the estimated volume 
TABLE 2: Comparison measurements made between first software and second software VOI measurement.

\begin{tabular}{|c|c|c|c|c|c|c|}
\hline \multicolumn{7}{|c|}{ Software measurements $(n=17)$} \\
\hline & $\begin{array}{c}\text { Mean } \pm \text { SD } \\
\text { first software }\end{array}$ & $\begin{array}{c}\text { Mean } \pm \text { SD } \\
\text { second software }\end{array}$ & $\begin{array}{c}\text { Mean difference } \\
\text { with } 95 \% \text { CI }\end{array}$ & ICC & Std. error difference & $P$ \\
\hline $\begin{array}{l}\text { Model bone } \\
\text { volume }\left(\mathrm{mm}^{3}\right)\end{array}$ & $387,71 \pm 12,49$ & $389,138 \pm 12,85$ & $-1,43$ & 0,93 & 4,35 & 0.75 \\
\hline
\end{tabular}

TABLE 3: Comparison measurements made between first manual and second manual VOI measurement.

\begin{tabular}{|c|c|c|c|c|c|c|}
\hline \multicolumn{7}{|c|}{ Manual measurement $(n=17)$} \\
\hline & $\begin{array}{l}\text { Mean } \pm \text { SD } \\
\text { first manual }\end{array}$ & $\begin{array}{c}\text { Mean } \pm \text { SD } \\
\text { second manual }\end{array}$ & $\begin{array}{c}\text { Mean difference } \\
\text { with } 95 \% \text { CI }\end{array}$ & ICC & Std. error difference & $P$ \\
\hline $\begin{array}{l}\text { Model bone } \\
\text { volume }\left(\mathrm{mm}^{3}\right)\end{array}$ & $381,24 \pm 12,57$ & $385,41 \pm 13,17$ & $-4,18$ & 0,90 & 4,41 & 0.35 \\
\hline
\end{tabular}

TABLE 4: The comparison measurement made between first software and first manual VOI measurement.

\begin{tabular}{|c|c|c|c|c|c|c|}
\hline & $\begin{array}{c}\text { Manual } \\
\text { Mean } \pm \text { SD } \\
\text { first software }\end{array}$ & $\begin{array}{c}\text { Software } \\
\text { Mean } \pm \text { SD } \\
\text { first manual }\end{array}$ & $\begin{array}{c}\text { Mean difference } \\
\text { with } 95 \% \mathrm{CI}\end{array}$ & ICC & Std. error difference & $P$ \\
\hline $\begin{array}{l}\text { Model bone } \\
\text { volume }\left(\mathrm{mm}^{3}\right)\end{array}$ & $387,71 \pm 15.0$ & $381,24 \pm 12,57$ & 6,48 & 0,97 & 4,30 & 0.14 \\
\hline
\end{tabular}

of the cleft and thus the amount of bone graft material that would be needed to fill the defect [22]. In these studies, the real volume is not calculated; they just use estimation.

A few latest studies had been made about the volumetric measurement accuracy such as the one made by Pinsky et al. [23] where the depth and diameter of simulated bone defects in an acrylic block and a human mandible were blindly measured electronically by five examiners using CBCT; the shape is cylindrical, so knowing the diameter and height, the volume is calculated manually. In our work the shape is simple but differs from the standard shape (cylindrical, cube, or sphere) and our volume was semiautomated calculated with algorithm implemented in software [18]. Overall, the present study demonstrates that clinically acceptable accuracy can be obtained for oral applications requiring evaluation of any change osseous volume. In addition, image segmentation and volume extraction have the potential to provide clinically useful information where accurate evaluation and volume changes over time are important.

However, these results are nonsignificant if we are to assume that the condition of the shape of the volume-ofinterest is simple and regular. But as in many cases needed by a dentist, the shape is irregular, so for the second study, we need to develop algorithms for automated segmentation (automated volume calculating) to evaluate the VOI in case of any shape needed clinically for assessment. This approach provides good and reproducible results but is consuming time and requires well-trained examiners. Also in this case, the automated segmentation is needed. This study presented a promising method, it allowed us to measure bone volume and this method provides an alternative to a data analysis.

\section{Conclusion}

We come to the conclusion that the comparison between software volume measurement using CBCT images and manual measurement is reliable and accurate. Therefore, the Image J software can be considered a precise method for measuring the oral bone volume.

\section{Conflict of Interests}

The authors certify that they have no commercial or associative interest that represents a conflict of interests in connection with the paper.

\section{References}

[1] D. Zhao, S. Zhang, X. Chen et al., "Evaluation of periodontitis and bone loss in patients undergoing hemodialysis," Journal of Periodontology, vol. 85, no. 11, pp. 1515-1520, 2014.

[2] S. Phothikhun, S. Suphanantachat, V. Chuenchompoonut, and K. Nisapakultorn, "Cone-beam computed tomographic evidence of the association between periodontal bone loss and mucosal thickening of the maxillary sinus," Journal of Periodontology, vol. 83, no. 5, pp. 557-564, 2012.

[3] K. De Faria Vasconcelos, K. M. Evangelista, C. D. Rodrigues, C. Estrela, T. O. De Sousa, and M. A. G. Silva, "Detection of periodontal bone loss using cone beam CT and intraoral radiography," Dentomaxillofacial Radiology, vol. 41, no. 1, pp. 64-69, 2012.

[4] H.-J. Langen, R. Fuhrmann, P. Diedrich, and R. W. Gunther, "Diagnosis of infra-alveolar bony lesions in the dentate alveolar 
process with high-resolution computed tomography. Experimental results," Investigative Radiology, vol. 30, no. 7, pp. 421426, 1995.

[5] M. K. Jeffcoat, "Current concepts in periodontal disease testing," The Journal of the American Dental Association, vol. 125, no. 8, pp. 1071-1078, 1994.

[6] M. S. Reddy, "Radiographic methods in the evaluation of periodontal therapy," Journal of Periodontology, vol. 63, no. 12, supplement, pp. 1078-1084, 1992.

[7] P. Eickholz and E. Hausmann, "Accuracy of radiographic assessment of interproximal bone loss in intrabony defects using linear measurements," European Journal of Oral Sciences, vol. 108, no. 1, pp. 70-73, 2000.

[8] D. R. Periago, W. C. Scarfe, M. Moshiri, J. P. Scheetz, A. M. Silveira, and A. G. Farman, "Linear accuracy and reliability of cone beam CT derived 3-dimensional images constructed using an orthodontic volumetric rendering program," Angle Orthodontist, vol. 78, no. 3, pp. 387-395, 2008.

[9] Y. Kim, J. U. Park, and Y. A. Kook, "Alveolar bone loss around incisors in surgical skeletal class III patients," The Angle Orthodontist, vol. 79, no. 4, pp. 676-682, 2009.

[10] K.-Y. Nahm, J.-H. Kang, S.-C. Moon et al., "Alveolar bone loss around incisors in Class I bidentoalveolar protrusion patients: a retrospective three-dimensional cone beam CT study," Dentomaxillofacial Radiology, vol. 41, no. 6, pp. 481-488, 2012.

[11] Y.-A. Kook, G. Kim, and Y. Kim, "Comparison of alveolar bone loss around incisors in normal occlusion samples and surgical skeletal Class III patients," Angle Orthodontist, vol. 82, no. 4, pp. 645-652, 2012.

[12] L. A. Feldkamp, L. C. Davis, and J. W. Kress, "Practical conebeam algorithm," Journal of the Optical Society of America A, vol. 1, no. 6, pp. 612-619, 1984.

[13] Y. Arai, E. Tammisalo, K. Iwai, K. Hashimoto, and K. Shinoda, "Development of a compact computed tomographic apparatus for dental use," Dentomaxillofacial Radiology, vol. 28, no. 4, pp. 245-248, 1999.

[14] P. Mozzo, C. Procacci, A. Tacconi, P. T. Martini, and I. A. Bergamo Andreis, "A new volumetric CT machine for dental imaging based on the cone-beam technique: preliminary results," European Radiology, vol. 8, no. 9, pp. 1558-1564, 1998.

[15] C. Y. Lee, T. M. Koval, and J. B. Suzuki, "Low-dose radiation risks of computerized tomography and cone beam computerized tomography: reducing the fear and controversy," Journal of Oral Implantology, vol. 41, no. 5, pp. e223-e230, 2015.

[16] A. G. Farman, "Applying DICOM to dentistry," Journal of Digital Imaging, vol. 18, no. 1, pp. 23-27, 2005.

[17] ImageJ Reference Software Version 1.48, http://rsb.info.nih.gov/ ij/download.html.

[18] Measure Stack Reference Software Version 0, 2002, http://www .optinav.com/MeasureStack.htm.

[19] M. Sheikhi, S. Ghorbanizadeh, M. Abdinian, H. Goroohi, and H. Badrian, "Accuracy of linear measurements of galileos cone beam computed tomography in normal and different head positions," International Journal of Dentistry, vol. 2012, Article ID 214954, 6 pages, 2012.

[20] R. Schulze, U. Heil, D. Groß et al., "Artefacts in CBCT: a review," Dentomaxillofacial Radiology, vol. 40, no. 5, pp. 265-273, 2011.

[21] L. N. Shiratori, J. Marotti, J. Yamanouchi, I. Chilvarquer, I. Contin, and P. Tortamano-Neto, "Measurement of buccal bone volume of dental implants by means of cone-beam computed tomography," Clinical Oral Implants Research, vol. 23, no. 7, pp. 797-804, 2012.
[22] F. A. Quereshy, G. Barnum, C. Demko et al., "Use of cone beam computed tomography to volumetrically assess alveolar cleft defects-preliminary results," Journal of Oral and Maxillofacial Surgery, vol. 70, no. 1, pp. 188-191, 2012.

[23] H. M. Pinsky, S. Dyda, R. W. Pinsky, K. A. Misch, and D. P. Sarment, "Accuracy of three-dimensional measurements using cone-beam CT," Dentomaxillofacial Radiology, vol. 35, no. 6, pp. 410-416, 2006 


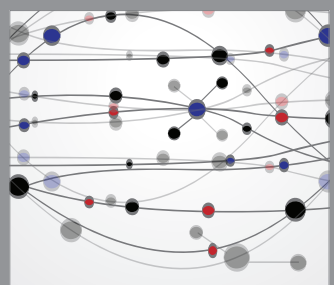

The Scientific World Journal
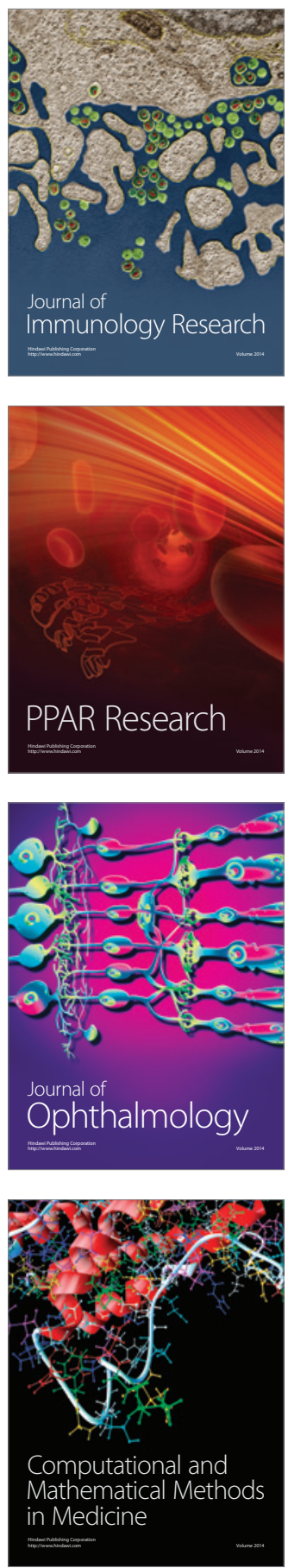

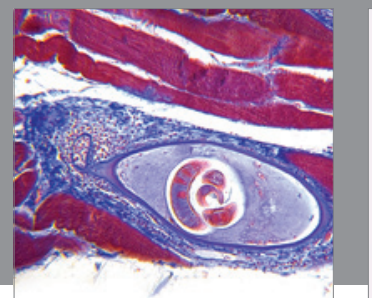

Gastroenterology

Research and Practice
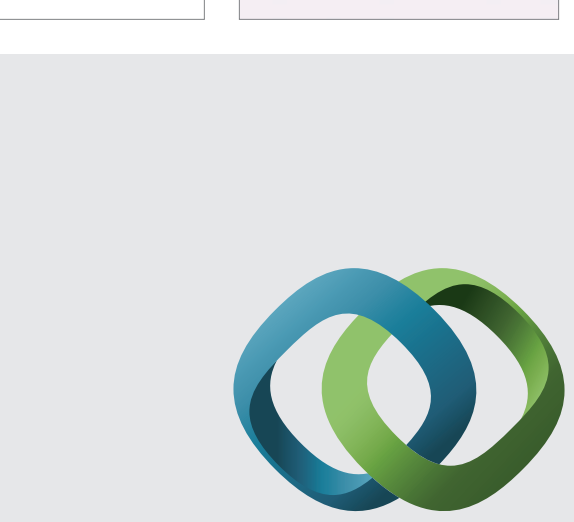

\section{Hindawi}

Submit your manuscripts at

http://www.hindawi.com
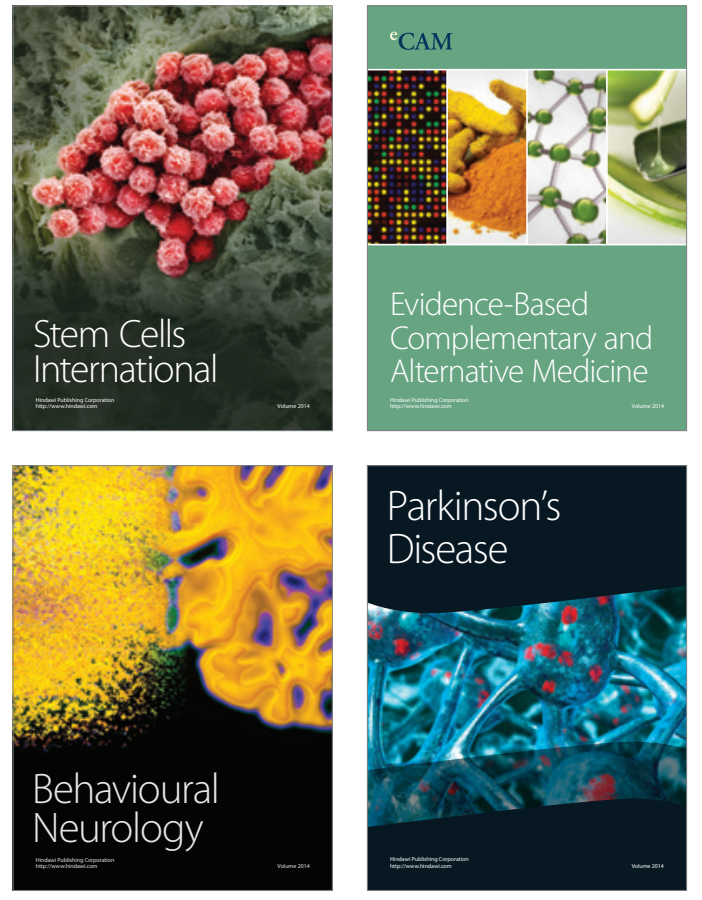
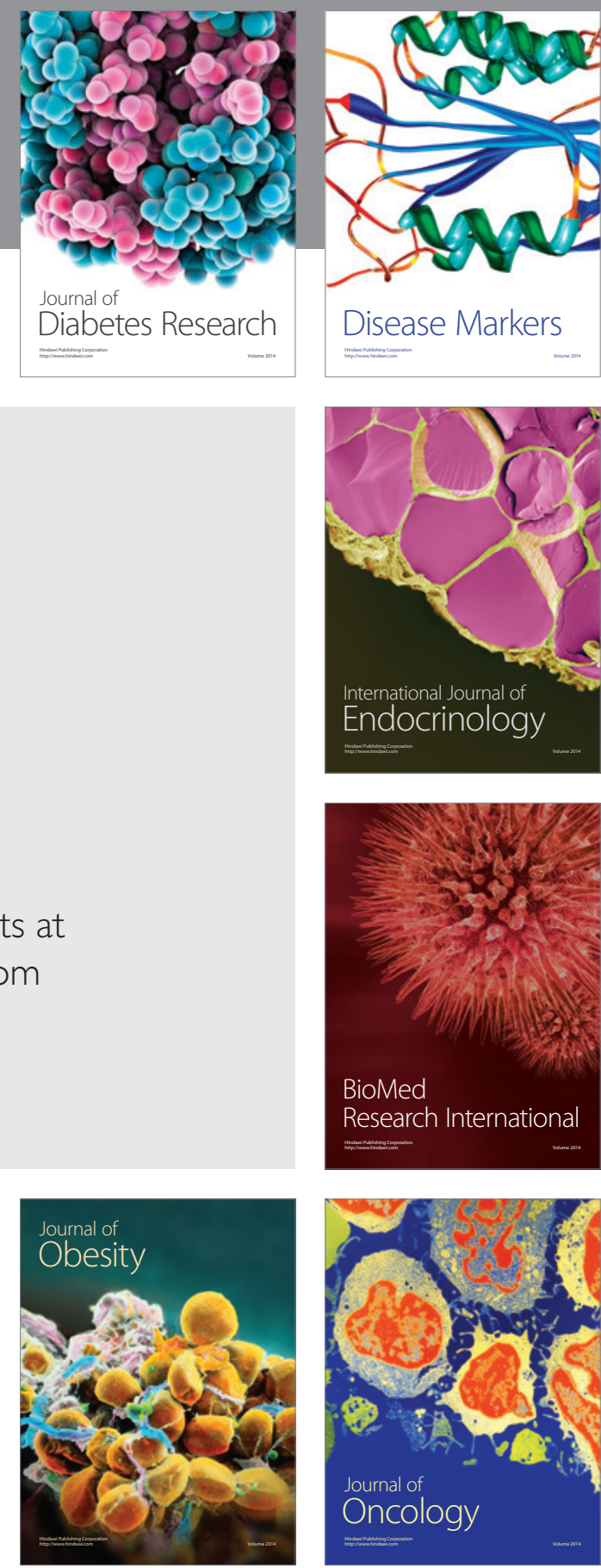

Disease Markers
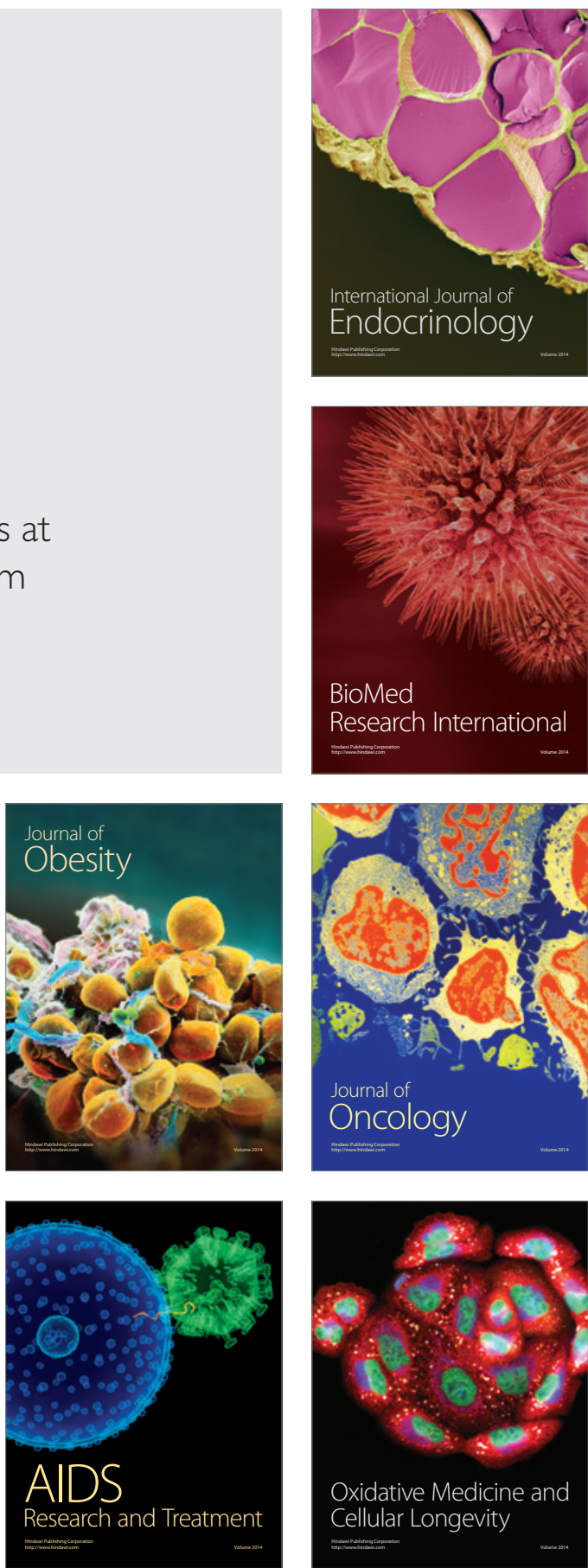